\title{
Construction and Evaluation of Gastric Cancer Risk Prediction Model
}

\author{
Y. YANG, Z. LONG*, ZHENGMING ZHONG, QING LIU AND X. YANG
}

Department of General Surgery, Chongqing City People's Hospital, Chongqing 400014, China

Yang et al.: Gastric Cancer Risk Prediction Model

\begin{abstract}
To predict the probability of gastric cancer and precancerous lesions in patients and construct a risk model for gastric cancer based on related risk factors. 189 patients with gastric cancer or precancerous lesions diagnosed by pathological examination in our hospital from October 2016 to May 2021 were selected as the experimental group and 203 patients with chronic gastritis during the same period as the control group. Collect the clinical data of the two groups of patients use single factor analysis to screen and then perform multifactor logistic regression analysis. To predict the effect, the Hosmer-Lemeshow goodness-of-fit test evaluates its degree of fit. Univariate analysis showed body mass index, family history of gastric cancer, Helicobacter pylori infection, serum pepsinogen I/II ratio, gastrin 17, fruit and vegetable intake, age of recipients, physical activity and radiation work history in patients with gastric cancer and precancerous lesions. All were higher than the control group $(\mathbf{p}<0.05)$. Logistic regression analysis showed that Helicobacter pylori infection, serum pepsinogen I/II ratio and gastrin 17 were independent risk factors for gastric cancer. The area under curve of the prediction model constructed based on these three indicators is 0.924 (95\% CI: 0.891 0.993) and its sensitivity and specificity are $82.41 \%$ and $94.93 \%$, respectively. The Hosmer-Lemeshow goodness-of-fit test result of the prediction model showed (Hosmer-Lemeshow $\mathrm{c}^{2}=13.301, \mathrm{p}=\mathbf{0 . 3 5 8}$ ), indicating that the prediction model has a good fit. Patients with Helicobacter pylori infection, serum pepsinogen I/II ratio and gastrin 17 are independent influencing factors. The prediction model established has good efficacy in predicting the risk of gastric cancer and precancerous lesions and can be used as a clinical guide for the prevention of gastric cancer.
\end{abstract}

Key words: Gastric cancer, serum pepsinogen I/II ratio, gastrin 17, tumor, Helicobacter pylori

Gastric cancer is a tumor with a very high mortality rate among gastrointestinal tumors ${ }^{[1,2]}$. There are many new methods for diagnosis. Gastric cancer is often found only after invading the muscularis propria. Because the early clinical symptoms of early gastric cancer are not obvious, the late stage is often accompanied by symptoms such as anemia, weight loss and inability to eat, the high mortality rate of gastric cancer is related to the poor treatment effect of surgery and chemotherapy on advanced gastric cancer patients and the lack of effective targeted therapy drugs ${ }^{[2-4]}$, its 5 y survival rate is only about $20 \%[5,6]$, so it is particularly important to pay attention to the epidemiology of gastric cancer and precancerous lesions and the early prevention of gastric cancer.

The occurrence of gastric cancer has made some progress in pathology, epidemiology, etiology, epigenetic changes and early prevention ${ }^{[4,7]}$. Studies have shown that Helicobacter pylori infection increases the incidence of gastric cancer ${ }^{[8]}$. The American Institute of Cancer Research (AICR) has concluded that salt intake and pickled foods may increase the incidence of gastric cancer ${ }^{[9]}$. A Korean cohort study shows that people who like to eat salty foods have a higher risk of gastric cancer than those who eat a light diet ${ }^{[10]}$ and confirmed familial adenomatous polyposis ${ }^{[11]}$. Peutz-Jeghers syndrome $^{[12]}$ and Single Nucleotide Polymorphisms (SNP) of $1 \mathrm{q} 22$ in the mucin 1 gene (MUC1) ${ }^{[13]}$ has a significant correlation with the occurrence of gastric cancer and studies have shown that Gastroesophageal Reflux Disease (GERD) is closely related to the risk of gastric cancer ${ }^{[14]}$.

*Address for correspondence

E-mail: looongo@sina.cn 
Early detection and early treatment of gastric cancer can prolong patient survival and reduce costs. Gastric cancer is one of the most common malignant tumors in my country. Gastric cancer has high deaths and poor prognosis and the incidence has regional differences ${ }^{[9,15]}$. Therefore, this study aims to find a simple and effective early gastric cancer screening measure in our province, find out the risk factors and build a model to improve the diagnosis rate of gastric cancer and provide a basis for preventing the occurrence of gastric cancer.

\section{MATERIALS AND METHODS}

\section{Research object:}

The clinical data of 392 patients treated in the Gastroenterology Department of our hospital from October 2016 to May 2020 were selected, gastric cancer and precancerous lesions diagnosed by gastroscopy and pathology (low and high-grade intraepithelial neoplasia; intestinal metaplasia of gastric mucosa). There were 189 cases and 203 patients diagnosed with chronic gastritis. The exclusion criteria of this study: no other malignant tumors; complicated with serious heart, lung and other medical diseases; patients with pregnant women and mental illness; patients who cannot actively cooperate. The study was reviewed and approved by the ethics committee of this hospital and the patient and his family signed an informed consent form.

\section{Data collection:}

Fill out a questionnaire for the patients visiting the Gastroenterology Department of our hospital. The survey content includes gender, age, height, weight, family history of gastric cancer, Helicobacter pylori infection, consumption of smoke, pickled products, fruit and vegetable intake, eating smoked and pickled products, physical activity, radiation work history, GERD, statin use, etc. All patients should fill in the questionnaire truthfully and a dedicated physician is responsible for filling in the patient's standard to ensure no missing items.

\section{Research methods:}

For patients considering gastric cancer or gastritis, gastroscopy and pathological examinations are performed. At the same time, fasting blood draws are tested for serum pepsinogen I (PGI), PGII and gastrin 17 (G-17) and carbon 14 breath test is also performed. According to the gastroscopy and pathology, the gastric cancer lesion group (experimental group) and gastritis group (control group) were divided; Through comparative analysis of gender, age, body mass index (BMI), family history of gastric cancer, Helicobacter pylori infection, consumption of smoke, pickled products, fruit and vegetable intake, consumption of smoke and pickled products, physical activity, PGI/II ratio, G-17, radiation work history, GERD, statin use and smoking history, etc., to find risk factors for gastric cancer; Based on the study of gastric precancerous diseases and risk factors of gastric cancer, a risk prediction model for high-risk groups of gastric cancer is established to assess the risk of gastric cancer.

\section{Statistical methods:}

Use Statistical Package For The Social Sciences (SPSS) 25.0 software for data statistics, qualitative data is expressed as a percentage and $\chi 2$ test is performed; quantitative data is expressed as $(\overline{\mathrm{x}} \pm \mathrm{s})$ and $\mathrm{t}$-test; univariate analysis and logistic regression analysis are used to find out the occurrence of gastric cancer and precancerous lesions risk factors and construct models; use Receiver Operator Characteristic (ROC) curve to determine the diagnosis points and evaluate the predictive effect of the model, Hosmer-Lemeshow goodness-of-fit test evaluates the degree of fit of the predictive model and $\mathrm{p}<0.05$ indicates that the difference is statistically significant.

\section{RESULTS AND DISCUSSION}

The single factor results showed that the two groups' gender, age, BMI index, family history of gastric cancer, Helicobacter pylori infection, consumption of smoke, pickled products, fruit and vegetable intake, consumption of smoke and pickled products, physical activity, There was no significant difference in PGI/II ratio, G-17, radiation work history, GERD and statin use $(\mathrm{p}>0.05)$; the preoperative BMI index, family history of gastric cancer and pyloric spiral of the two groups of patients compared with bacillus infection, PGI/II ratio, G-17, physical activity and radiation work history, the difference was statistically significant $(p<0.05)$. See Table 1.

In the single factor analysis of risk factors, there are risk factors for early infection after liver transplantation (BMI index, family history of gastric cancer, Helicobacter pylori infection, PGI/II ratio, G-17, fruit and vegetable intake, recipients age, physical activity and radiation work history) were substituted into the multivariate logistic regression model (Table 2). The results showed that Helicobacter pylori infection, PGI/ II ratio and G-17 were independent predictors of gastric cancer (all $\mathrm{p}<0.05$, Table 2 ). Table 3 shows the predictive power, sensitivity and specificity of Helicobacter pylori infection, PGI/II ratio and G-17. 
www.ijpsonline.com

TABLE 1: SINGLE FACTOR ANALYSIS OF RISK FACTORS FOR GASTRIC CANCER

\begin{tabular}{|c|c|c|c|c|}
\hline Factor & Test group $(n=189)$ & Control group $(n=203)$ & $t / c^{2}$ & $\mathrm{p}$ \\
\hline Gender & & & 0.146 & 0.743 \\
\hline Male & $112(59.26)$ & $113(55.67)$ & & \\
\hline Female & 77 (40.74) & $90(54.33)$ & & \\
\hline Age & $57.24 \pm 16.34$ & $41.24 \pm 14.92$ & 1.075 & 0.042 \\
\hline BMI $\left(\mathrm{kg} / \mathrm{m}^{2}\right) \geq 25$ & $110(58.20)$ & $46(22.66)$ & 8.613 & 0.024 \\
\hline Smoking history & & & 0.316 & 0.521 \\
\hline Yes & $67(35.45)$ & $64(31.53)$ & & \\
\hline No & $122(64.55)$ & $139(68.47)$ & & \\
\hline $\begin{array}{l}\text { Family history of } \\
\text { gastric cancer }\end{array}$ & & & 10.531 & 0.001 \\
\hline Yes & $56(29.63)$ & $16(7.89)$ & & \\
\hline No & $132(71.37)$ & $187(92.11)$ & & \\
\hline $\begin{array}{l}\text { Helicobacter pylori } \\
\text { infection }\end{array}$ & & & 15.545 & 0.001 \\
\hline Yes & $125(66.14)$ & $41(20.20)$ & & \\
\hline No & $64(33.86)$ & $162(79.80)$ & & \\
\hline $\begin{array}{l}\text { Edible smoked and } \\
\text { pickled products }\end{array}$ & & & 0.758 & 0.813 \\
\hline occasionally & $132(69.84)$ & $143(70.44)$ & & \\
\hline often & $57(30.16)$ & $60(29.56)$ & & \\
\hline $\begin{array}{l}\text { Fruit and vegetable } \\
\text { intake }\end{array}$ & & & 1.624 & 0.039 \\
\hline occasionally & $108(57.14)$ & $23(11.33)$ & & \\
\hline often & $81(42.86)$ & $180(78.67)$ & & \\
\hline Taking antioxidants & & & 0.349 & 0.534 \\
\hline Yes & 17 (8.99) & $19(6.40)$ & & \\
\hline No & $172(91.01)$ & $184(93.60)$ & & \\
\hline $\begin{array}{l}\text { Taking non-steroidal } \\
\text { anti-inflammatory drugs }\end{array}$ & & & 0.125 & 0.921 \\
\hline Yes & 19 (17.99) & $26(12.81)$ & & \\
\hline No & $170(82.01)$ & $177(87.19)$ & & \\
\hline physical activities & & & 5.421 & 0.023 \\
\hline occasionally & $146(77.25)$ & $89(43.84)$ & & \\
\hline often & $43(22.75)$ & $114(56.16)$ & & \\
\hline $\mathrm{PGI} /$ Il ratio & & & 16.621 & 0.001 \\
\hline$>3$ & $36(19.05)$ & $151(74.38)$ & & \\
\hline$<3$ & $152(80.95)$ & $52(25.62)$ & & \\
\hline G-17 & & & 12.641 & 0.001 \\
\hline$>16 \mathrm{pmol} / \mathrm{l}$ & $143(75.66)$ & $64(31.53)$ & & \\
\hline$<16 \mathrm{pmol} / \mathrm{l}$ & $46(24.34)$ & $139(68.47)$ & & \\
\hline Radiation work history & & & 1.977 & 0.036 \\
\hline No & $152(80.42)$ & $193(95.07)$ & & \\
\hline Yes & $37(19.58)$ & $10(5.93)$ & & \\
\hline
\end{tabular}

Note: PGI/II: Serum pepsinogen I/II G-17: Gastrin 17

Special Issue 5, 2021 
TABLE 2: MULTIVARIATE LOGISTIC REGRESSION ANALYSIS RESULTS OF GASTRIC CANCER

\begin{tabular}{lccccc}
\hline Factor & $\mathrm{B}$ & Wald $\chi^{2}$ & $\mathrm{p}$ value & OR value & $95 \% \mathrm{Cl}$ \\
\hline PGI/II ratio & 1.062 & 16.003 & $<0.001$ & 2.631 & $1.103 \sim 3.521$ \\
$\begin{array}{l}\text { Helicobacter pylori } \\
\text { infection }\end{array}$ & 1.231 & 10.082 & $<0.001$ & 2.867 & $1.419 \sim 5.422$ \\
G-17 & 1.427 & 9.673 & $<0.001$ & 3.813 & $1.401 \sim 6.286$ \\
BMI & 0.134 & 1.856 & 0.069 & 2.054 & $1.204 \sim 4.103$ \\
$\begin{array}{l}\text { Family history of } \\
\text { gastric cancer }\end{array}$ & 1.259 & 0.720 & 0.072 & 0.753 & $0.283 \sim 2.063$ \\
$\begin{array}{l}\text { physical activities } \\
\text { Radiation work }\end{array}$ & 0.079 & 0.741 & 0.085 & 1.113 & $0.546 \sim 2.234$ \\
$\begin{array}{l}\text { history } \\
\text { Age }\end{array}$ & 1.084 & 1.093 & 0.083 & 0.942 & $0.305 \sim 2.041$ \\
$\begin{array}{l}\text { Fruit and vegetable } \\
\text { intake }\end{array}$ & 0.753 & 1.145 & 0.359 & 0.986 & $0.342 \sim 2.114$ \\
\hline
\end{tabular}

TABLE 3: ROC CURVE ANALYSIS OF DIFFERENT PREDICTIVE FACTORS ON GASTRIC CANCER PREDICTION MODEL

\begin{tabular}{lcccccc}
\hline Variable & AUC & $95 \% \mathrm{Cl}$ & $\mathrm{P}$ & Cutoff value & Sensitivity & Specificity \\
\hline PGI/II ratio & 0.795 & $0.698 \sim 0.883$ & $<0.001$ & 0.54 & $82.92 \%$ & $89.87 \%$ \\
$\begin{array}{l}\text { Helicobacter } \\
\text { pylori infection }\end{array}$ & 0.685 & $0.575 \sim 0.835$ & $<0.001$ & 0.49 & $76.67 \%$ & $84.03 \%$ \\
G-17 & 0.784 & $0.682 \sim 0.875$ & $<0.001$ & 0.52 & $79.64 \%$ & $87.89 \%$ \\
\hline
\end{tabular}

Note: PGI/II: Serum pepsinogen I/II G-17: Gastrin 17

In the logistic regression analysis interface, based on the aforementioned analysis results, select the PGI/II ratio, Helicobacter pylori infection, and G-17 as the "Covariates" option and then select the gastric cancer as the "Dependent" option. After running the program, the prediction model can be completely established and can automatically generate the predicted value under the model and draw the ROC curve under the model through the predicted value (fig. 1), it can be seen that the Area Under Curve (AUC) is 0.924 (95 \% CI: 0.891 0.993), the cutoff value is 0.669 and the corresponding sensitivity and specificity are 82.41 $\%$ and $94.93 \%$, respectively. It can be seen that the prediction efficiency, sensitivity and specificity of the model are significantly better than each single index. As shown in fig. 2, the results of the Hosmer-Lemeshow goodness-of-fit test of the prediction model show that the difference between the predicted value of the model and the actual observation value is not statistically significant (Hosmer-Lemeshow $\mathrm{c}^{2}=13.301, \mathrm{p}=0.358$ ), suggesting the prediction model that, fit is good.

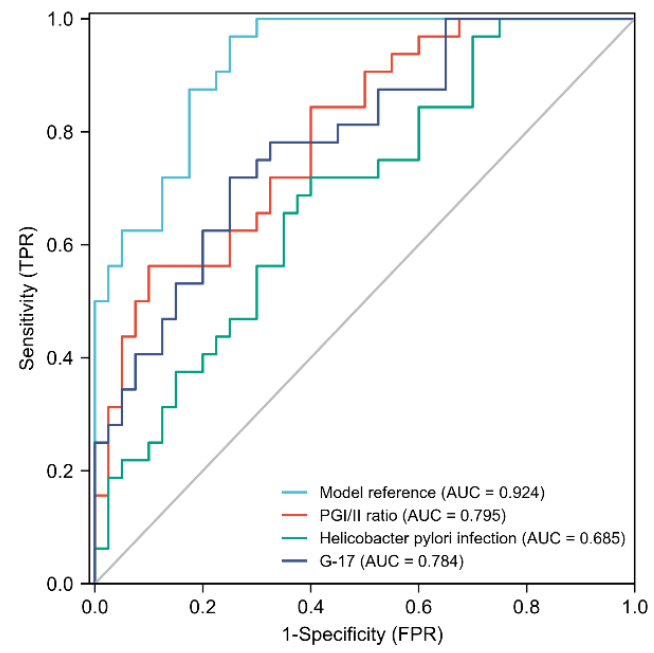

Fig. 1: ROC curve analysis of various factors and prediction models, ( - ) Model reference (AUC = 0.924); ( - ) PGI/II ratio (AUC $=0.685)$; G-17 (AUC = 0.784); ( - ) Helicobacter pylori infection $(\mathrm{AUC}=0.685) ;(-) \mathrm{G}-17$ (AUC $=0.685)$ 


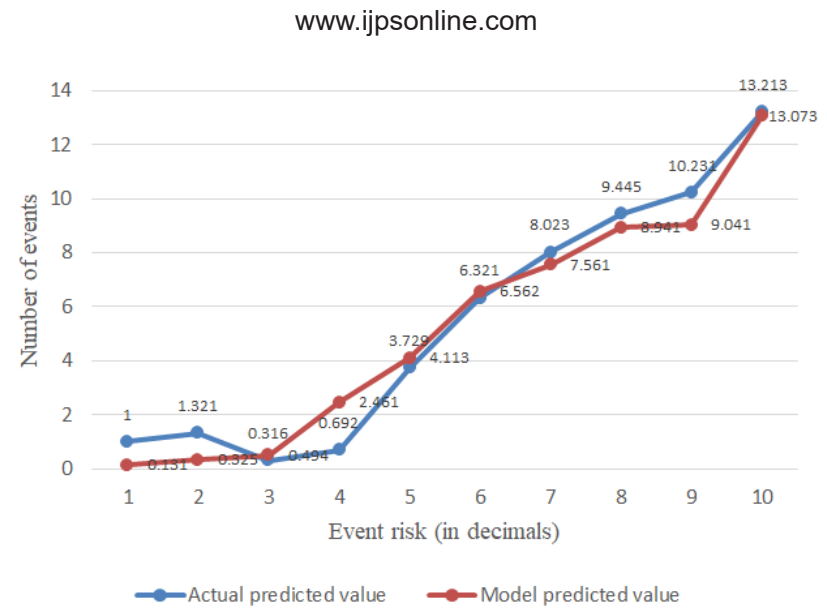

Fig. 2: The goodness of fit curve of the gastric cancer risk prediction model, $(-)$ Actual predicted value; $(\rightarrow)$ Model predicted value

Gastric cancer is one of the main causes of death from gastrointestinal tumors ${ }^{[15]}$. Studies have shown that gastric cancer patients increase by about 990000 people worldwide each year, of which about 738000 patients die of gastric cancer ${ }^{[16]}$. The high mortality rate is related to the early symptoms of patients. Nothing special, most patients have been found to have metastasized. There are regional and ethnic differences in the incidence of gastric cancer in the world. The incidence of gastric cancer in individuals also changes with age ${ }^{[17,18]}$, which gives us the risk of gastric cancer. Factors have brought challenges. In our analysis of gastric cancer risk factors, the multivariate regression model showed that Helicobacter pylori infection, PGI/ II ratio and G-17 are independent risk factors for gastric cancer. Provide data reference for early prevention of gastric cancer.

The results of single factor analysis in this study showed that BMI index, family history of gastric cancer; Helicobacter pylori infection, PGI/II ratio, G-17, fruit and vegetable intake, recipient age, physical activity and radiation work history were compared. The difference is statistically significant $(p<0.05)$; the meaningful factors are included in the logistic regression analysis and the meaningful modeling factors (Helicobacter pylori infection, PGI/II ratio, G-17) are screened to construct the model and the model is detected. The statistical value of Hosmer and Leme-show test is 13.301 ( $p>0.05)$, which indicates that the model fits well between the real equation and the fitted equation. In this study, the ROC curve was used to evaluate the prediction model of patients with gastric cancer and precancerous lesions. The area under the curve was 0.924 and the sensitivity and specificity were $82.41 \%$ and $94.93 \%$, respectively, indicating that the prediction effect is good. Logistic regression analysis showed that Helicobacter pylori infection,
PGI/II ratio less than 3 and G-17 greater than 16 pmol/1 were independent risk factors for gastric cancer and precancerous lesions $(\mathrm{p}<0.05)$. Analysis of the reasons may be: Helicobacter pylori infection and gastric cancer are usually proved to be closely related and proved to be a clear cause of gastric cancer. It is currently uncertain how Helicobacter pylori cause gastric cancer. Helicobacter pylori infection mainly causes direct or indirect inflammation of gastric epithelial cells and can also regulate epithelial cell functions, such as Cag A, which promotes the development of gastric cancer in two ways. Helicobacter pylori infection accounts for $65 \%-80 \%$ of gastric cancer patients ${ }^{[19-21]}$; In patients with gastric cancer and precancerous lesions, the level of serum pepsinogen PGI/II ratio not only represents the serum level of PGI or PGII, but also reflects the trend indicator of PGI and PGII serum expression. The serum PGI/II ratio is now widely used as a screening test for gastric cancer. At present, the research on the relationship between PGs expression and gastric cancer is not enough. In this study, the serum expression of PGI and PGII between patients with gastric cancer and gastritis is different and the ratio is used to assess the risk of gastric cancer ${ }^{[22-24]}$; Gastrin passed inducing the expression and function of anti-apoptotic proteins affect the carcinogenic process and increase the proliferation of gastric mucosal cells by activating transcription genes. At the same time, gastrin-stimulated human gastric epithelial cells express matrix metalloproteinase 9 , which increases the invasion and metastasis of gastric cancer cells. Gastrinemia is a high risk factor for gastric cancer $^{[25,26]}$.

At the same time, a large number of studies have shown that age, male, ethnicity, family history of gastric cancer and susceptibility syndrome, smoking, alcoholism, exposure to radiation, eating habits, etc., are all related to the occurrence of gastric cancer ${ }^{[27]}$. 
The research found that the incidence of gastric cancer increases with age. The incidence of gastric cancer in male smoking patients is higher than that in women ${ }^{[28]}$. Studies have shown that the incidence of gastric cancer in whites is twice that of other races ${ }^{[29]}$. Long-term follow-up of the disasters in Hiroshima and Nagasaki Studies have shown that radiation has been identified as a high-risk risk factor for gastric cancer ${ }^{[30]}$. Early diagnosis of gastric cancer is still difficult worldwide and it is difficult to make a correct diagnosis under endoscopy in the early stage ${ }^{[14,31]}$.

The two main limitations of this study are its retrospective study. The clinical data comes from a single center. More clinical cases are needed to summarize the risk factors of gastric cancer and precancerous lesions. In summary, patients with Helicobacter pylori infection, PGI/II ratio less than 3, and G-17 greater than $16 \mathrm{pmol} / 1$ are independent influencing factors. The prediction model established based on these three indicators has good performance in predicting the risk of gastric cancer. It can provide an important reference for clinically guiding the early prevention, management and treatment of gastric cancer.

\section{Conflict of interests:}

The authors declared no conflicts of interest.

\section{REFERENCES}

1. Brenner H, Rothenbacher D, Arndt V. Epidemiology of stomach cancer. Cancer Epidemiol 2009;472:467-77.

2. Venneman K, Huybrechts I, Gunter MJ, Vandendaele L, Herrero R, Van Herck K. The epidemiology of Helicobacter pylori infection in Europe and the impact of lifestyle on its natural evolution toward stomach cancer after infection: A systematic review. Helicobacter 2018;23(3):e12483.

3. Bailey C: Stomach cancer. Clin Evid 2006;(15):765-71.

4. Johnston FM, Beckman M. Updates on management of gastric cancer. Curr Oncol Rep 2019;21(8):1-9.

5. Strong VE. Progress in gastric cancer. Updates $\mathrm{S}$ 2018;70(2):157-9.

6. Deng W, Jin L, Zhuo H, Vasiliou V, Zhang Y. Alcoıvı consumption and risk of stomach cancer: A meta-analysis. Chem Biol Interact 2021;336:109365.

7. Park SH, Lim DH, Sohn TS, Lee J, Zang DY, Kim ST, et sl A randomized phase III trial comparing adjuvant single-ag S1, S-1 with oxaliplatin, and postoperative chemoradiat with S-1 and oxaliplatin in patients with node-positive gastric cancer after D2 resection: the ARTIST 2 trial. Ann Oncol 2021;32(3):368-74.

8. Stojanovic MM, Rancic NK, Andjelkovic Apostolovic MR, Ignjatovic AM, Ilic MV. Trends of Stomach Cancer in Central Serbia. Medicina 2021;57(7):665.

9. Poorolajal J, Moradi L, Mohammadi Y, Cheraghi Z, GohariEnsaf F. Risk factors for stomach cancer: a systematic review and meta-analysis. Epidemiol Health 2020;42:e2020004.
10. Smyth EC, Nilsson M, Grabsch HI, van Grieken NC, Lordick F. Gastric cancer. Lancet 2020;396(10251):635-648.

11. Eusebi LH, Telese A, Marasco G, Bazzoli F, Zagari RM. Gastric cancer prevention strategies: a global perspective. J Gastroenterol Hepatol 2020;35(9):1495-502.

12. Stewart OA, Wu F, Chen Y. The role of gastric microbiota in gastric cancer. Gut Microbes 2020;11(5):1220-30.

13. Fu JX, Zou YN, Long-Li XJ. Widespread Metastasis to the Stomach 10 Years After Primary Breast Cancer: A case report and review of the literature. Medicine 2020;99(48):e22527.

14. Kong X, Yang S, Liu C, Tang H, Chen Y, Zhang X, et al. Relationship between MEG3 gene polymorphism and risk of gastric cancer in Chinese population with high incidence of gastric cancer. Biosci Rep 2020;40(11):BSR20200305.

15. Kono K, Nakajima S, Mimura K. Current status of immune checkpoint inhibitors for gastric cancer. Gastric Cancer 2020;23(4):565-78.

16. Li Z, Wu C, Wu J, Ji M, Shi L, Jiang J, et al. Synergistic antitumor effects of combined deguelin and cisplatin treatment in gastric cancer cells. Oncol Lett 2014;8(4):1603-7.

17. Sharfo AW, Stieler F, Kupfer O, Heijmen BJ, Dirkx $\mathrm{ML}$, Breedveld $\mathrm{S}$, et al. Automated VMAT planning for postoperative adjuvant treatment of advanced gastric cancer. Radiat Oncol 2018;13(1):74.

18. Zhang J, Qiu WQ, Zhu H, Liu H, Sun JH, Chen Y, et al. Hot air contributes to the carcinogenesis of gastric cancer via modulating cellular and exosomal miRNAs level. Cell Death Dis 2020;11(9):780.

19. Ma LC, Tian XY, Gao F, Dong WJ, Dang T, Jia YB. Association analysis between SNPs in LATS1 and LATS2 and non-cardia gastric cancer. BMC gastroenterol 2020;20(1):155.

20. Thanaphongdecha P, Karinshak SE, Ittiprasert W, Mann VH, Chamgramol Y, Pairojkul C, et al. Infection with helicobacter pylori induces epithelial to mesenchymal transition in human cholangiocytes. Pathogens 2020;9(11):971.

21. Toyoshima O, Nishizawa T, Arita M, Kataoka Y, Sakitani K, Yoshida S, et al. Helicobacter pylori infection in subjects negative for high titer serum antibody. World J Gastroenterol 2018;24(13):1419-28.

22. Li P, He C, Sun L, Dong N, Yuan Y. Pepsinogen I and II expressions in situ and their correlations with serum pesignogen levels in gastric cancer and its precancerous disease. BMC Clin Pathol 2013;13(1):1-22.

23. Yuan L, Zhao JB, Zhou YL, Qi YB, Guo QY, Zhang HH, et al. Type I and type II Helicobacter pylori infection status and their impact on gastrin and pepsinogen level in a gastric cancer prevalent area. World J Gastroenterol 2020;26(25):3673-85.

24. Re VD, Zorzi MD, Caggiari L, Repetto O, Brisotto G, Magris $\mathrm{R}$, et al. Polymorphisms in pepsinogen $\mathrm{C}$ and miRNA genes associate with high serum pepsinogen II in gastric cancer patients. Microorganisms 2021;9(1):126.

25. He SW, Shen KQ, He YJ, Xie B, Zhao YM. Regulatory effect and mechanism of gastrin and its antagonists on colorectal carcinoma. World J Gastroenterol 1999;5(5):408-416.

26. Takaishi S, Tu S, Dubeykovskaya ZA, Whary MT, Muthupalani $\mathrm{S}$, Rickman $\mathrm{BH}$, et al. Gastrin is an essential cofactor for helicobacter-associated gastric corpus carcinogenesis in C57BL/6 mice. Am J Pathol 2009;175(1):365-75.

27. Ma M, Chen S, Zhu BY, Zhao BW, Wang HS, Xiang J, et al. The clinical significance and risk factors of solitary lymph node metastasis in gastric cancer. PLoS One 2015;10(1):e0114939. 
28. Kim YM, Kim JH, Baik SJ, Chun J, Youn YH, Park H. Sarcopenia and sarcopenic obesity as novel risk factors for gastric carcinogenesis: A health checkup cohort study. Front Oncol 2019;9:1249.

29. Wang C, Jia Z, Cao D, You L, Jin $\mathrm{M}$, Wu X, et al. Polymorphism of DNA methyltransferase $3 \mathrm{~b}$ and association with development and prognosis in gastric cancer. PloS one 2015;10(8):e0134059.

30. Yang JY, Kim JB, Lee P, Kim SH. Evodiamine Inhibits Helicobacter pylori Growth and Helicobacter pylori-Induced Inflammation. Int J Mol Sci 2021;22(7):3385.
31. Yang L, Cui M, Zhang L, Song L. FOXM1 facilitates gastric cancer cell migration and invasion by inducing Cathepsin D. Oncotarget 2017;8(40):68180-90.

This is an open access article distributed under the terms of the Creative Commons Attribution-NonCommercial-ShareAlike 3.0 License, which allows others to remix, tweak, and build upon the work non-commercially, as long as the author is credited and the new creations are licensed under the identical terms

This article was originally published in a special issue, "Diagnostic and Therapeutic Advances in Biomedical Research and Pharmaceutical Sciences"

Indian J Pharm Sci 2021:83(5) spl issue "112-118" 